\title{
Small mammal fauna from Wulanhuxiu (Nei Mongol, China) implies the Irdinmanhan-Sharamurunian (Eocene) faunal turnover
}

Qian Li, Yuan-Qing Wang, and Łucja Fostowicz-Frelik

Acta Palaeontologica Polonica 61 (4), 2016: 759-776 doi:http://dx.doi.org/10.4202/app.00292.2016

Wulanhuxiu, a middle Eocene locality in the Erlian Basin, Nei Mongol (China) has been commonly regarded as belonging to the Ulan Shireh Formation, equated with the Irdin Manha Formation. We recognized two separate mammalian faunas of different age from the beds exposed at Wulanhuxiu. The lower fossiliferous horizon contains an anagalid, uncommon duplicidentate representatives (Gomphos progressus sp. nov., Mimolagus, Erenlagus, and Strenulagus ), and diverse perissodactyls. This combination of taxa points to an Irdinmanhan age, but one element of the fauna (Schlosseria) may represent an Arshantan relic. Overall, the assemblage comprises "paleoplacental" mammals mixed with "neoplacentals". The upper horizon is less species-rich and the only paleoplacentals present are scarce creodonts. However, this horizon is marked by abundant remains (including postcranial material) of the lagomorph Gobiolagus and by the presence of an advanced form of Gobiomys (Rodentia), and is most probably Sharamurunian in age. Thus, Wulanhuxiu documents replacement, albeit incomplete, of paleoplacentals by neoplacentals in the Chinese Eocene record.

Key words: Mammalia, Rodentia, Duplicidentata, Anagalidae, Eocene, Ulan Shireh Formation, China, Erlian Basin.

Qian Li [liqian@ivpp.ac.cn] and Yuan-Qing Wang [wangyuanqing@ivpp.ac.cn], Key Laboratory of Vertebrate Evolution and Human Origins, Institute of Vertebrate Paleontology and Paleoanthropology, Chinese Academy of Sciences, Beijing 100044, China. Łucja Fostowicz-Frelik [1fost@twarda.pan.pl] (corresponding author), Institute of Paleobiology, Polish Academy of Sciences, ul. Twarda 51/55, PL 00-818 Warsaw, Poland.

This is an open-access article distributed under the terms of the Creative Commons Attribution License (for details please see creativecommons.org), which permits unrestricted use, distribution, and reproduction in any medium, provided the original author and source are credited. 
FoF Full text $(958.7 \mathrm{kB})$ 